\title{
A cross-sectional analysis of health literacy: patient- versus family doctor-reported and associations with self-efficacy and chronic disease
}

Stephanie Stock ${ }^{1} \mathbb{0}$, Sibel Altin ${ }^{2}$, Farah Nawabi ${ }^{1} \mathbb{B}$, Daniele Civello ${ }^{1} \mathbb{B}$, Arim Shukri ${ }^{1}$, Marcus Redaèlli $^{1}$ and Adrienne Alayli ${ }^{1 *}$ (i)

\begin{abstract}
Background: Adequate health literacy $(\mathrm{HL})$ levels contribute to good health outcomes and successful disease self-management in patients with chronic disease. Hence, it is essential that family doctors recognize patients with inadequate HL in need of additional support. This study had two aims: (1) to assess and compare patient self-reported versus family doctor-rated HL estimates, and (2) to explore associations between patient-reported HL, self-efficacy and chronic diseases.

Methods: Participants in this cross-sectional survey were recruited through general practices in North RhineWestphalia, Germany. Patient self-reported HL was measured using the European Health Literacy Survey-16. Family doctor-rated HL was measured with an adapted version of this instrument. Using crosstabulations patient-reported and family doctor-rated $\mathrm{HL}$ estimates were compared for 346 patient-family doctor pairs. Associations between $\mathrm{HL}$, self-efficacy and chronic disease were investigated using regression analyses.

Results: Patient-reported and family doctor-rated HL estimates were concordant in $38 \%$ of all cases. On average family doctors rated their patients' $\mathrm{HL}$ lower than patients rated their own $\mathrm{HL}$. The lower average family doctor ratings were more pronounced when patients were older, male and had more than one chronic disease. Female family doctors rated HL of male patients lower than their male colleagues. Patient reported HL had a significant positive association with self-efficacy. Mediation analysis provided support that self-efficacy acts as mediator between $\mathrm{HL}$ and the number of chronic diseases.

Conclusions: Our study findings indicate a significant discrepancy between patients'self-reported $\mathrm{HL}$ and externally rated $\mathrm{HL}$ by family doctors. A more systematic utilization of $\mathrm{HL}$ screeners might help reduce this discrepancy. At the same time, consideration should be given to enhancing communication training for family doctors and addressing critical HL skills in patient education.
\end{abstract}

Keywords: Health literacy, General practice, Self-efficacy, Chronic disease, Multimorbidity, Sex/gender

*Correspondence: adrienne.alayli@uk-koeln.de

${ }^{1}$ Institute for Health Economics and Clinical Epidemiology, University of Cologne, Faculty of Medicine and University Hospital Cologne, Gleueler Str. 176-178, 50924 Cologne, Germany

Full list of author information is available at the end of the article

\section{Background}

Health literacy (HL) describes the ability to access, understand, appraise and apply (health-) information to make informed decisions regarding healthcare [1]. Adequate health literacy is important to achieve good 
health outcomes in chronic care [2,3]. Health literacy also emerges as predictor for inequalities in health, because patients with higher HL levels are more likely to utilize preventive health services and exhibit better disease self-management [4-8]. The latter is crucial for coping with chronic disease and for maintaining a high quality of life [9].

Family doctors in Germany serve a high proportion of chronically ill patients. Their ability to judge their patients' HL adequately can help identify patients in need of additional support. Screening patients HL is not common in the general practice setting. Rather, family doctors often subconsciously use their patients' education status, appearance, or manner of speaking as proxy [10].

Few studies investigate physicians' ability to judge their patients' HL [11-13]. Mechanisms involved in the relationship between HL and chronic disease outcomes are still poorly understood [14]. Several patient- and systemrelated factors have been proposed as mediators in the causal pathways linking health literacy and health outcomes [15]. Increasingly, research suggests patient selfefficacy as a mediator and hence as potential intervention target to positively affect chronic disease outcomes [16, 17]. Repeatedly, studies have demonstrated that selfefficacy is positively associated with HL [18] and that self-efficacy predicts disease self-management behaviors [19]. The evidence on pathways between HL, self efficacy and chronic disease outcomes is however limited to date $[17,20]$. Evidence is also lacking regarding the relationship between HL and multimorbidity, the co-occurrence of two or more chronic diseases [21]. Insights into factors affecting a patients' number of chronic diseases are necessary to better understand mechanisms involved in preventing and delaying multimorbidity.

This study assessed family doctors' ratings of their patients' HL compared to patient self-reported HL in a general practice setting. We also explored associations between patient reported HL, self-efficacy and the number of chronic diseases.

\section{Methods}

Between October 2015 and December 2017 an invitation to participate in the cross-sectional survey was faxed to 208 general practices in the German state of North Rhine-Westphalia. A member of the research team visited practices who expressed an interest to participate $(\mathrm{n}=11)$ to provide further information and enrol family doctors in the study. Patients were recruited by their family doctors during regular consultations. A member of the research team was present in the participating practices on previously scheduled dates to support the recruitment process and provide information to patients eligible for participation.
Patients were included if they were at least 18 years of age, spoke German, and had at least two consultations with their family doctor during the past 12 months.

\section{Measures}

Patients' self-reported HL was measured using the German version of the European Health literacy Survey HLSEU-16 [22]. Family doctors rated their patients' HL with an adapted version of the HLS-EU-16 in which questions were reframed so family doctors could answer as proxies for their patients. The version was pretested by the study team with family doctors in their practices.

The HLS-EU-16 is a 16-item short version of the HLSEU built on a conceptual model of HL after an extensive literature review [22]. It measures four HL skills with respect to information processing (i.e. accessing, understanding, appraising, and applying health information) in three settings (i.e. healthcare, prevention, health promotion). On a scale ranging from "very easy" to "very difficult", patients indicate how easy it is for them to perform different activities. The short version has acceptable psychometric properties, and its sum score correlates highly with the sum score of the long version $(r=0.82)$ [23]. Following the scoring system suggested by the developers of the instrument all items were dichotmised by collapsing the two adjoining categories and a simple sum score across the 16 binary items was calculated. Based on the sum score three levels of health literacy were distinguished, using the same cut-off values as other international versions: inadequate $($ score $\leq 8)$, problematic (score $>8$ and $\leq 12$ ), and adequate (score $>12$ ). Only respondents with at least 14 valid answers were included in further analyses [23].

We used a general measure of self-efficacy to measure patients' perception of their ability to perform across a variety of different situations [24]. The general selfefficacy short form (Allgemeine Selbstwirksamkeit Kurzskala, ASKU) [25] is a validated short instrument with 3 items, scored on a 5-point Likert scale (Table 1). For the analysis, the mean of each item is calculated and compared with a reference table. Psychometric properties are acceptable $(r=0.86)$ [25].

\section{Data analyses}

Demographic variables and HL questions were analysed using descriptive statistics. The patient sample was split into subgroups based on their HL levels (i.e. inadequate, problematic and adequate). In case of disagreement, a distinction was made into "moderate disagreement " (difference by one level) and "marked disagreement " (difference by two levels). Differences in mean scores between patient self-reported and family doctor rated HL were compared using t-tests. Multivariate linear regression 
Table 1 Items of the ASKU

\begin{tabular}{|c|c|c|c|c|c|}
\hline Items $^{a}$ & $\begin{array}{l}\text { do not agree } \\
\text { at all }\end{array}$ & hardly agree & $\begin{array}{l}\text { somewhat } \\
\text { agree }\end{array}$ & mostly agree & $\begin{array}{l}\text { completely } \\
\text { agree }\end{array}$ \\
\hline 1. I can rely on my own abilities in difficult situations & $\square$ & $\square$ & $\square$ & $\square$ & $\square$ \\
\hline 2. I am able to solve most problems on my own & $\square$ & $\square$ & $\square$ & $\square$ & $\square$ \\
\hline 3. I can usually solve even challenging and complex tasks well & $\square$ & $\square$ & $\square$ & $\square$ & $\square$ \\
\hline
\end{tabular}

${ }^{a}$ Items are derived from Beierlein et al. 2013 [25]. The authors of this article have translated the original items from German into English. An official translation into English is underway: Doll, E., Nießen, D., Schmidt, I., Rammstedt, B., \& Lechner, C. M. (2020). The General Self-Efficacy Short Scale-3 (GSE-3): An English-language adaptation. Manuscript in preparation

analyses were conducted to investigate associations of patient-reported HL estimates with self-efficacy and chronic disease to assess for evidence of mediation. Results were considered significant in case of $\mathrm{p}<0.05$. All analyses were conducted using IBM $^{\circledR}$ SPSS $^{\circledR}$ Statistics for Windows, version 26.0 [26-32].

\section{Results}

Eleven practices with twenty-eight family doctors were enrolled in the study. Completed surveys were returned from fourteen family doctors in eight practices. Characteristics of the family doctors and practices included in the survey are summarized in Table 2.

The participating family doctors recruited 346 patients of whom $93.8 \%$ were chronically ill. Response rates to the patient survey were $96 \%$ and $100 \%$ to the family doctor survey respectively. Characteristics of the patient sample are displayed in Table 3.

The majority $(52.9 \%)$ of patients surveyed rated their HL levels as adequate, $32.8 \%$ as problematic, and $14.3 \%$ as inadequate.

Stratified analyses of the HL sum score showed that patients with employment and high education level had significantly higher self-reported HL levels $(p=0.002$; $p=0.005)$. Stratified analyses by age $(p=0.995)$, sex

Table 2 Characteristics of participating family doctors and practices

\begin{tabular}{|c|c|c|c|}
\hline \multicolumn{2}{|l|}{ Characteristic } & Number & Percent \\
\hline \multicolumn{4}{|c|}{ Family doctors $(n=14)$} \\
\hline \multirow[t]{2}{*}{ Gender } & Male & 9 & 64.3 \\
\hline & Female & 5 & 35.7 \\
\hline \multicolumn{4}{|c|}{ Participating practices $(\mathrm{n}=8)$} \\
\hline \multirow{4}{*}{$\begin{array}{l}\text { Number of patients } \\
\text { Enrolled }^{a}\end{array}$} & $\geq 500-1000$ & 1 & 14.3 \\
\hline & $>1000-1500$ & 3 & 42.9 \\
\hline & $>1500-2000$ & 2 & 28.6 \\
\hline & $>2000$ & 1 & 14.3 \\
\hline \multirow[t]{2}{*}{ Type } & Single practice & 3 & 37.5 \\
\hline & Group practice & 5 & 62.5 \\
\hline \multirow[t]{2}{*}{ Location } & Metro & 6 & 75.0 \\
\hline & Urban & 2 & 25.0 \\
\hline
\end{tabular}

${ }^{a}$ Data for one practice is missing $(\mathrm{p}=0.474)$ and migration $(\mathrm{p}=0.640)$ background indicated no significant differences in self-reported HL.

Patient-reported versus family doctor-rated health literacy Figure 1 shows proportions of the adequate, problematic and inadequate HL categories in patient self-reported and family doctor-rated HL estimates.

Patient-reported and family doctor-rated HL estimates were concordant in $38 \%$ of all cases. In $40.8 \%$ of the cases the estimates differed moderately, and in $21.1 \%$ markedly. Family doctors' estimates of their patients' HL were higher than patients' self-assessment in $22.9 \%$ of cases. Family doctors' estimates were lower than their patients' HL estimates in $39.0 \%$ of the cases. Patient-reported and family doctor reported HL were most frequently concordant in the adequate HL category (26\%) and least frequently concordant in the inadequate HL category (4\%).

Mean difference scores (MDS) between patientreported and family doctor-rated HL estimates are presented in Table 4. On average family doctors' HL ratings were lower than their patients' self-reported HL. Stratified analyses showed that the lower family doctor ratings were significantly more pronounced when patients were older, male and had more than one chronic disease.

The lower family doctor ratings were also more pronounced when female doctors carried out HL ratings. This difference was not significant, however (see Table 4). Further stratification by both patient sex and family doctor sex showed that female family doctors in our sample underestimated HL of male patients to a larger extent than their male colleagues (female family doctors: $\mathrm{MDS}=3.41$ for male vs. 0.51 for female patients, $\mathrm{p}=0.042$; male family doctors: $\mathrm{MDS}=2.06$ for male vs. 0.87 for female patients, $\mathrm{p}=0.191$ ).

\section{Associations of patient-reported health literacy with self-efficacy and chronic disease}

Stepwise regression analyses showed that the explained variance in patients' self-efficacy improved significantly by including the patients' HL sum score as predictor in a model consisting of socio-demographic predictors 
Table 3 Characteristics of the patient sample

\begin{tabular}{|c|c|c|c|c|c|}
\hline & & & & Number & Percent \\
\hline \multirow[t]{2}{*}{ Gender ${ }^{a}$} & Female & & & 200 & 57.8 \\
\hline & Male & & & 135 & 39.0 \\
\hline \multirow[t]{2}{*}{$A g e^{b}$} & $\leq 60$ years & & & 164 & 47.4 \\
\hline & $>60$ years & & & 165 & 47.7 \\
\hline \multirow[t]{2}{*}{ Employment status $^{c}$} & Notworking & & & 166 & 48.0 \\
\hline & Working & & & 166 & 48.0 \\
\hline \multirow[t]{3}{*}{ Education leveld } & Low & & & 144 & 41.6 \\
\hline & Moderate & & & 89 & 25.7 \\
\hline & High & & & 102 & 29.5 \\
\hline \multirow[t]{2}{*}{ Migration background } & No Migration background & & & 253 & 73.1 \\
\hline & With migration background & & & 77 & 22.3 \\
\hline \multirow[t]{4}{*}{ Number of chronic diseases ${ }^{f}$} & None & & & 21 & 6.1 \\
\hline & 1 & & & 101 & 29.2 \\
\hline & 2 & & & 98 & 28.3 \\
\hline & 3 ormore & & & 121 & 35.0 \\
\hline \multirow[t]{11}{*}{ Chronic diseases $^{f}$} & Cardiovascular disease & & & 183 & 53.7 \\
\hline & Backpain & & & 150 & 44.0 \\
\hline & $\begin{array}{l}\text { Depression or other } \\
\text { Mental disorders }\end{array}$ & & & 84 & 24.6 \\
\hline & Diabetes & & & 82 & 24.0 \\
\hline & Chronic obstructive pulmonary disease & & & 56 & 16.4 \\
\hline & Cancer & & & 36 & 10.6 \\
\hline & Rheumatism & & & 35 & 10.3 \\
\hline & Stroke & & & 16 & 4.7 \\
\hline & Chronic kidney disease & & & 6 & 1.8 \\
\hline & Other & & & 101 & 29.6 \\
\hline & $\mathrm{n}$ & Mean & SD & Min & Max \\
\hline$A g e^{b}$ & 329 & 57.9 & 16.4 & 19 & 89 \\
\hline ASKU Score $e^{9, *}[1=$ low to $5=$ high $]$ & 341 & 3.9 & 0.8 & 1 & 5 \\
\hline $\begin{array}{l}\text { HLS-EU-16 Score }{ }^{* *}[0=10 w / \text { no HL to } 16=h i g h \\
\text { HL] }\end{array}$ & 293 & 12.2 & 3.3 & 1 & 16 \\
\hline
\end{tabular}

Missing data: ${ }^{a} 11,{ }^{b} 17,{ }^{c} 14,{ }^{d} 11, e 16,{ }^{f} 5,{ }^{9} 5$

*The ASKU score is calculated by taking the mean of the three items

**Patient self-reported, only includes respondents with at least 14 valid answers

only (see Table 5). In this model only education level and HL had a significant independent contribution to self-efficacy.

Mediation analyses were conducted to test the hypothesis that patients' self-efficacy mediates the relationship between HL and the number of chronic diseases. In line with this hypothesis, we found a significant positive association between HL and self-efficacy (beta $=0.102$, $\mathrm{p}=0.000)$ and a significant negative association between self-efficacy and number of chronic diseases (beta $=-0.289, p=0.005$ ). The association between HL and chronic diseases was negative as expected, however did not reach significance (beta $=-0.024, \mathrm{p}=0.317$ ).

\section{Discussion}

This study assessed concordance between patients' selfreported and family doctor-estimated HL for chronically ill patients in a general practice setting. It also explored associations between patient-reported HL, self-efficacy and the number of chronic diseases.

The distribution of self-reported HL in our patient sample compares to the distribution for adults equal or above 60 years in the German general population and can be judged to be fairly representative [33]. International research indicates that a lower education and being male are associated with lower HL levels [34, 35]. This could only be reproduced for education in our sample. In contrast to previous general population data [36], 


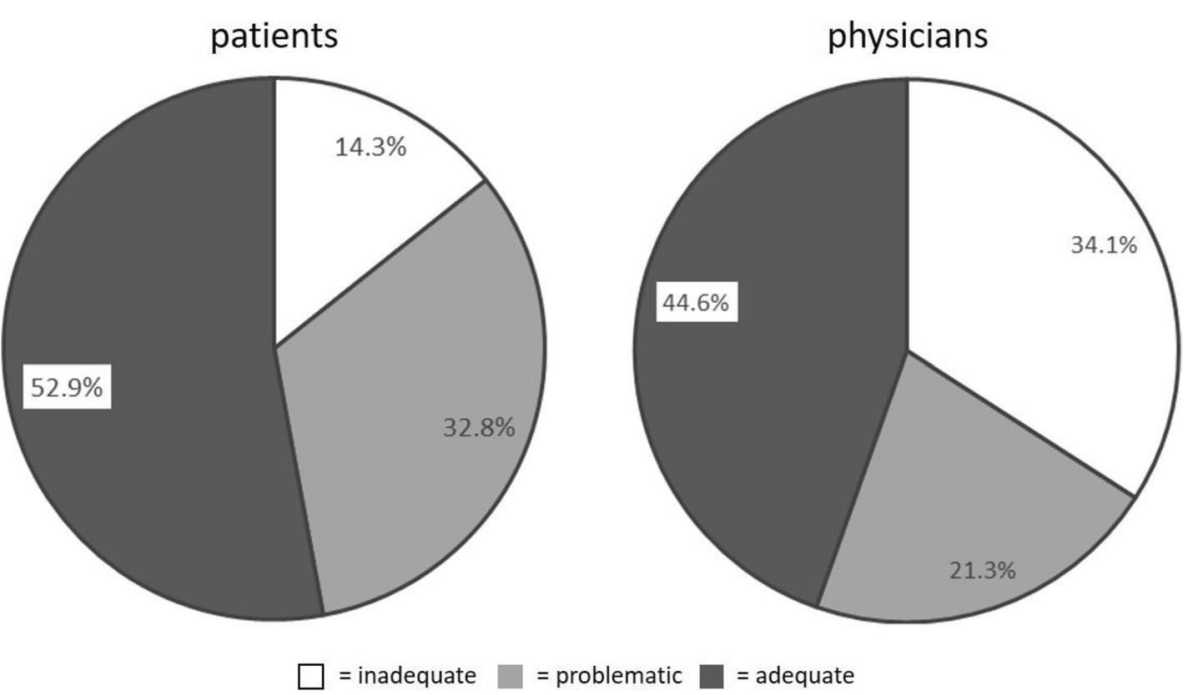

Fig. 1 Patient-reported versus family doctors-rated HL levels (\%)

Table 4 Comparison of Mean HL Scores

\begin{tabular}{llll}
\hline Full analysis & & $\begin{array}{l}\text { Mean } \\
\text { difference } \\
\text { score }\end{array}$ & p \\
\hline HLS-Score patient (12.44) & & 1.42 & $<0.001$ \\
HLS-Score family doctor (11.01) & & & \\
Stratified analyses & $>60$ & 2.75 & $0.001^{* *}$ \\
Patient characteristics & $\leq 60$ & 0.23 & \\
Age & Male & 2.38 & $0.032^{*}$ \\
Gender & Female & 0.75 & \\
& Yes & 1.47 & 0.976 \\
Migration background & No & 1.50 & \\
& $\leq 1$ & -0.01 & $0.007^{* *}$ \\
Number of chronic diseases & $>1$ & 2.11 & \\
Family doctor characteristics & & & 0.849 \\
Gender & Male & 1.38 & \\
& Female & 1.53 & \\
\hline
\end{tabular}

${ }^{*} p<.05{ }^{* *} p<.01$

participants with migration background did not have lower HL levels in our study. The relatively high education levels of migrants included in our study might be responsible for this finding. Compared to the average of the German population [37] patients in our sample more often had a higher school education or degree that qualified for university entrance.

Analyses of patient-reported versus family doctor-rated HL estimates showed that these were concordant in $38 \%$ of the cases. This limited concordance was also found by
Table 5 Linear regression models

\begin{tabular}{llllll}
\hline Independent variables & $\mathbf{R}^{2}$ & $\mathbf{R}^{2}$ change & $\mathbf{B}$ & $\mathbf{S E}$ & $\mathbf{p}$ \\
\hline Model 1 & 0.078 & 0.078 & & & \\
Gender & & & 0.104 & 0.094 & 0.268 \\
Age & & & 0.163 & 0.104 & 0.119 \\
Migration background & & & -0.149 & 0.106 & 0.161 \\
Education level & & & 0.186 & 0.056 & $0.001^{* *}$ \\
Employment status & & & 0.239 & 0.101 & $0.018^{*}$ \\
Model 2 & 0.231 & 0.153 & & & \\
Gender & & & 0.100 & 0.086 & 0.244 \\
Age & & & 0.070 & 0.096 & 0.469 \\
Migration background & & & -0.121 & 0.097 & 0.214 \\
Education level & & & 0.112 & 0.053 & $0.033^{*}$ \\
Employment status & & & 0.103 & 0.094 & 0.273 \\
HL & & & 0.094 & 0.013 & $0.000^{* * *}$ \\
${ }^{*} p<.05{ }^{* *} p<.011^{* * *} p<.001$ & & & & \\
dependent variable $=$ ASKU score & & & &
\end{tabular}

the few available international studies, which have shown an overestimation of patients' HL by physicians in primary care and other health care providers [11-13, 38]. In contrast to these studies, the present survey shows that in a German general practice setting family doctors on average rate their patients' HL lower than patients rate their own HL. A possible explanation could be the use of a more sophisticated instrument in this study.

This study identified several factors affecting the concordance between family doctors' ratings and patients' self-reported HL. Ratings were most frequently concordant in patients with adequate HL (26\%) and least frequently concordant in patients with inadequate $\mathrm{HL}(4 \%)$. 
The lower average family doctor ratings found in our sample were more pronounced when patients were older, male and had more than one chronic disease.

The tendency of family doctors to provide lower HLratings for elderly patients ( $>60$ years of age) might be explained by the perception of a general decrease of $\mathrm{HL}$ with age as observed in the European HL Study [34] and US studies [39, 40].

The lower family doctor ratings for male patients might be attributed to the observation that men engage less in seeking health information, screening programs and health promoting behaviors than women [41-43]. This phenomenon is documented by an increasing body of research, yet an unterstanding of specific mechanisms leading to sex and gender-based differences in health behaviors are currently lacking [44, 45]. Interestingly, female family doctors in our study rated HL of male patients lower than their male colleagues. This difference suggests that male and female doctors may have different perceptions about health literacy of male and female patients. This finding is concordant with other studies observing differences in clinical judgements regarding male and female patients based on physicians' sex [46].

Family doctors in our study rated their patients HL significantly lower when they had more than one chronic disease. This may suggest that family doctors make inferences about HL levels based on the assumption that multimorbidity is are determined by patients' lifestyle choices. Evidence is emerging that unhealthy lifestyle choices, such as low levels of physical activity and smoking increase the likelihood of multimorbidity [47, 48]. A scientific basis for an association between HL and multimorbidity is currently lacking, but it is possible that this association exists for specific combinations of diseases [21] or specific HL profiles [49].

In line with previous studies investigating the relationship between HL and self-efficacy among patients with diabetes and heart failure [50-52], we found a significant positive association between HL and self-efficacy among chronically ill patients. Mediation analysis provided support that self-efficacy acts as mediator between HL and the number of chronic diseases.

\section{Strenghts and limitations}

A strength of our study is the relatively large number of patient-family doctor pairs surveyed and the high response rate of patients and doctors in the participating practices. The use of an adapted version of the HLS-EU-16 to derive family doctor-rated HL estimates is another strength. Previous studies have relied on single-item tools, asking family doctors to directly assign patients to a certain health literacy level [11-13, 38]. A limitation is that we had to rely on self-reports for all outcomes and thus could not validate patients' or family doctors' HL estimation against an objective standard. Second, participation was voluntary for practices, family doctors and patients. Hence, we cannot preclude selection bias.

\section{Clinical implications}

This study provides further evidence that family doctors have difficulties in rating their patients' HL. The finding that family doctor HL ratings were significantly lower for older patients, male patients, and patients with more than one chronic disease suggests that family doctors make inferences about patients' HL based on other variables. Additionally, we found that ratings of patients HL differed between male and female family doctors. Consequently, family doctors cannot optimally tailor interactions to their patients' HL levels. This underscores the importance that family doctors either use objective tools to screen patients regarding their HL or use plain language in interactions with all patients. Both strategies have pros and cons. Xu et al. [53] conclude that clear explanations from physicians have the potential to improve patients' HL (specifically communicative and critical HL) and self-efficacy. This may support the request that physicians should use plain language with all patients [53]. Seligman et al. [10] report that physicians respond to patients identified with low HL with changed communication patterns, but at the same time feel less satisfied with the visit. Other challenges with institutionalized screening programs relate to time barriers and shaming patients [54]. To enhance patient-centered communication physicians need training in applying screening tools and communication techniques for patients with low HL. Confirming whether patients understand the information provided (e.g., using the teach-back method [55]) and strategies to enhance patients' self-efficacy are also essential steps in improving self-management education.

\section{Future research}

Qualitative research is essential to understand why family doctors have difficulties judging their patients' HL. It can also provide further insights into sex/gender-based differences in family doctor ratings. Existing training approaches for health professionals to adapt to their patients' HL-levels are useful, but require further development and testing [56, 57]. Short HL screeners like the one from Chew et al. [58] show promising results. Further validation studies in different settings and populations are recommended to facilitate use of the screener in routine practice [58]. Future studies should also focus on refining alternative methods to estimate patient $\mathrm{HL}$ levels 
from routine primary care health records [59]. Finally, gender influences in patient-doctor interaction should be further investigated. Gender-sensitive approaches have been identified as an important factor in patient-centeredness of care, that need consideration in addition to patients HL levels [60].

\section{Conclusion}

The results of this study show that there is a significant discrepancy between patients' self-reported HL and external assessment of HL by their family doctors. It is possible that the systematic use of HL screeners by family doctors could help reduce this discrepancy. To avoid patient stigmatisation consideration should be given to incorporating communication training into all family physician training curricula and to addressing critical HL skills in traditional patient education.

\section{Abbreviations \\ HL: Health literacy; HLS-EU: European Health Literacy Survey; ASKU: Allge- meine Selbstwirksamkeit Kurzskala.}

\section{Acknowledgements}

The authors would like to thank all family doctors and patients who participated in this study.

\section{Authors' contributions}

SS, MR and SA developed the study protocol. MR was responsible for recruiting general practitices. SA, MR and FN were responsible for data collection in the general practices and coordination of the research project. AS and DC conducted the data analysis. SS wrote the initial draft of the manuscript. AA reviewed and revised the manuscript. All authors approved the final version of the manuscript.

\section{Funding}

This project was funded by a grant of the German Federal Ministry of Education and Research (BMBF) (01EL1425B); Study registration number: DRKS00010402. The funding body had no role in the design of the study, the collection, analysis and interpretation of data, or in writing the manuscript. Open Access funding enabled and organized by Projekt DEAL.

\section{Availability of data and materials}

The datasets generated and/or analysed during the current study are not publicly available due to their containing information that could compromise the privacy of research participants. However, summarised data are available upon reasonable request.

\section{Declarations}

\section{Ethics approval and consent to participate}

The Universtiy Hospital of Cologne ethics committee granted ethical approval for the study (ID Number16-084). Both family doctors and patients provided written informed consent. The study was performed in accordance with the Declaration of Helsinki.

\section{Consent for publication}

Not applicable.

\section{Competing interests}

The authors declare that they have no competing interests.

\section{Author details}

${ }^{1}$ Institute for Health Economics and Clinical Epidemiology, University of Cologne, Faculty of Medicine and University Hospital Cologne, Gleueler Str. 176-178, 50924 Cologne, Germany. ${ }^{2}$ AOK Rheinland/Hamburg, Hamburg, Germany.

Received: 4 December 2020 Accepted: 19 August 2021

Published online: 15 September 2021

References

1. Sorensen K, Van den Broucke S, Fullam J, et al. Health literacy and public health: a systematic review and integration of definitions and models. BMC Public Health. 2012;12(1):80.

2. Berkman ND, Sheridan SL, Donahue KE, Halpern DJ, Crotty K. Low health literacy and health outcomes: an updated systematic review. Ann Intern Med. 2011;155(2):97-107.

3. Dewalt DA, Berkman ND, Sheridan S, Lohr KN, Pignone MP. Literacy and health outcomes: a systematic review of the literature. J Gen Intern Med. 2004;19(12):1228-39.

4. Heijmans M, Waverijn G, Rademakers J, van der Vaart R, Rijken M. Functional, communicative and critical health literacy of chronic disease patients and their importance for self-management. Patient Educ Couns. 2015;98(1):41-8.

5. Rachmawati U, Sahar J, Wati DNK. The association of diabetes literacy with self-management among older people with type 2 diabetes mellitus: a cross-sectional study. BMC Nurs. 2019;18(Suppl 1):34.

6. van der Heide I, Wang J, Droomers M, Spreeuwenberg P, Rademakers J, Uiters $E$. The relationship between health, education, and health literacy: results from the Dutch Adult Literacy and Life Skills Survey. J Health Commun. 2013;18(Suppl 1):172-84.

7. Bennett IM, Chen J, Soroui JS, White S. The contribution of health literacy to disparities in self-rated health status and preventive health behaviors in older adults. Ann Fam Med. 2009;7(3):204-11.

8. Kim S, Love F, Quistberg DA, Shea JA. Association of health literacy with self-management behavior in patients with diabetes. Diabetes Care. 2004;27(12):2980-2

9. Holman H, Lorig K. Patient self-management: a key to effectiveness and efficiency in care of chronic disease. Public Health Rep. 2004;119(3):239-43

10. Seligman HK, Wang FF, Palacios JL, et al. Physician notification of their diabetes patients' limited health literacy: A randomized, controlled trial. J Gen Intern Med. 2005:20(11):1077.

11. Bass PF, Wilson JF, Griffith CH, Barnett DR. Residents' ability to identify patients with poor literacy skills. Acad Med. 2002;77(10):1039-41.

12. Kelly PA, Haidet P. Physician overestimation of patient literacy: a potential source of health care disparities. Patient Educ Couns. 2007;66(1):119-22.

13. Storms H, Aertgeerts B, Vandenabeele F, Claes N. General practitioners' predictions of their own patients' health literacy: a cross-sectional study in Belgium. BMJ Open. 2019;9(9): e029357.

14. van der Heide I, Uiters E, Rademakers J, Struijs JN, Schuit AJ, Baan CA. Associations among health literacy, diabetes knowledge, and selfmanagement behavior in adults with diabetes: results of a dutch crosssectional study. J Health Commun. 2014;19(Suppl 2):115-31.

15. Paasche-Orlow MK, Wolf MS. The causal pathways linking health literacy to health outcomes. Am J Health Behav. 2007;31(Suppl 1):S19-26. https:// doi.org/10.5555/ajhb.2007.31.supp.S19 (PMID: 17931132).

16. Huang YM, Shiyanbola OO, Chan HY. A path model linking health literacy, medication self-efficacy, medication adherence, and glycemic control. Patient Educ Couns. 2018;11:1906-13. https://doi.org/10.1016/j.pec.2018. 06.010.

17. Lee YJ, Shin SJ, Wang RH, Lin KD, Lee YL, Wang YH. Pathways of empowerment perceptions, health literacy, self-efficacy, and self-care behaviors to glycemic control in patients with type 2 diabetes mellitus. Patient Educ Couns. 2016;99(2):287-94. https://doi.org/10.1016/j.pec.2015.08.021.94

18. Guo X, Zhai X, Hou B. Adequacy of health literacy and its effect on diabetes self-management: a meta-analysis. Aust J Prim Health. 2020;26:45865. https://doi.org/10.1071/PY20079. 
19. Tan F, Oka P, Dambha-Miller H, Tan N. The association between selfefficacy and self-care in essential hypertension: a systematic review. BMC Family Practice 2021;22 (44). https://doi.org/10.1186/s12875-021-01391-2

20. Osborn CY, Paasche-Orlow MK, Bailey SC, Wolf MS. The mechanisms linking health literacy to behavior and health status. Am J Health Behav. 2011;35(1):118-28. https://doi.org/10.5993/ajhb.35.1.11.

21. Hudon, C, Fortin, M, Poitras ME. The relationship between literacy and multimorbidity in a primary care setting. BMC Fam Pract 2012; 13 (33) https://doi.org/10.1186/1471-2296-13-33.

22. The HLS-EU Consortium 2012. Measurement of health literacy in Europe: HLS-EU-Q47; HLS-EU-Q16; and HLS-EU-Q86.

23. Röthlin F, Pelikan J, Ganahl K. Health literacy of 15-year-old adolescents in Austria. https://oepgk.at/wp-content/uploads/2020/02/bericht_die_ gesundheitskompetenz_von_15-jaehrigen_jugendlich.pdf. Accessed 05.05.2020.

24. Maddux JE. Measurement of General Self-Efficacy. In: Zeigler-Hill V, Shackelford TK. Encyclopedia of Personality and Individual Differences. Springer; 2017.

25. Beierlein C, Kemper CJ, Kovaleva A, Rammstedt B. Short Scale for Measuring General Self-efficacy Beliefs (ASKU). Mda. 2013;7(2):251-278252.

26. Hayes AF, Matthes J. Computational procedures for probing interactions in OLS and logistic regression: SPSS and SAS implementations. Behav Res Methods. 2009;41(3):924-36.

27. Preacher KJ, Hayes AF. SPSS and SAS procedures for estimating indirect effects in simple mediation models. Behav Res Methods Instrum Comput. 2004;36(4):717-31.

28. Fiedler K, Schott M, Meiser T. What mediation analysis can (not) do. J Exp Soc Psychol. 2011;47(6):1231-6.

29. Hayes AF. Introduction to Mediation, Moderation, and Conditional Process Analysis: A Regression-Based Approach. New York, NY: Guilford Publications; 2013.

30. Hayes AF. Introduction to Mediation, Moderation, and Conditional Process Analysis: A Regression-Based Approach. 2nd ed. New York, NY: Guilford Publications; 2018.

31. Hayes AF, Rockwood NJ. Regression-based statistical mediation and moderation analysis in clinical research: Observations, recommendations, and implementation. Behav Res Ther. 2017;98:39-57.

32. Frazier PA, Tix AP, Barron KE. Testing moderator and mediator effects in counseling psychology research. J Couns Psychol. 2004;51(1):115.

33. Jordan S, Hoebel J. Health literacy of adults in Germany: Findings from the German Health Update (GEDA) study. Bundesgesundheitsblatt Gesundheitsforschung Gesundheitsschutz. 2015;58(9):942-50.

34. Sorensen K, Pelikan JM, Rothlin F, et al. Health literacy in Europe: comparative results of the European health literacy survey (HLS-EU). Eur J Public Health. 2015;25(6):1053-8.

35. Davis SN, Wischhusen JW, Sutton SK, et al. Demographic and psychosocial factors associated with limited health literacy in a community-based sample of older Black Americans. Patient Educ Couns. 2020;103(2):385-91.

36. Schaeffer D, Vogt D, Berens E, Hurrelmann K. Gesundheitskompetenz der Bevölkerung in Deutschland: Ergebnisbericht. Bielefeld: Universität Bielefeld, Fakultät für Gesundheitswissenschaften; 2016. https://doi.org/ 10.2390/0070-pub-29081112.

37. Destatis. Bildung in Deutschland 2020. Bielefeld: Autorengruppe Bildungsberichterstatttung; 2020. https://doi.org/10.3278/6001820gw.

38. Dickens C, Lambert BL, Cromwell T, Piano MR. Nurse overestimation of patients' health literacy. J Health Commun. 2013;18(Suppl 1):62-9.

39. Gazmararian JA, Baker DW, Williams MV, et al. Health literacy among Medicare enrollees in a managed care organization. JAMA. 1999;281(6):545-51

40. Kobayashi LC, Wardle J, Wolf MS, von Wagner C. Aging and Functional Health Literacy: A Systematic Review and Meta-Analysis. J Gerontol B Psychol Sci Soc Sci. 2016;71(3):445-57.

41. Hiller J, Schatz K, Drexler H. Gender influence on health and risk behavior in primary prevention: a systematic review. J Public Health. 2017;25:33949. https://doi.org/10.1007/s10389-017-0798-z.
42. Bidmon S, Terlutter R. Gender Differences in Searching for Health Information on the Internet and the Virtual Patient-Physician Relationship in Germany: Exploratory Results on How Men and Women Differ and Why. J Med Internet Res; 2015; 17(6): e156. https://doi.org/10.2196/jmir.4127.

43. Mauvais-Jarvis F, Merz NB, Barnes PJ, Brinton RD, Carrero J. Sex and gender: modifiers of health, disease, and medicine. Lancet. 2020;396:565-82.

44. Aldin A, Chakraverty D, Baumeiste A, Monsef I, Noyes J. Gender differences in health literacy of migrants: a synthesis of qualitative evidence. Cochrane Database of Systematic Reviews 2019, Issue 4. Art. No.: CD013302. https://doi.org/10.1002/14651858.CD013302. Accessed 11 June 2021.

45. Oliffe $J$, Rossnagel E, Kelly MT, Bottorff JL, Seaton C, Darroch F. Men's health literacy: a review and recommendations. Health Promot Int. 2020;35(5):1037-51. https://doi.org/10.1093/heapro/daz077.

46. Champagne-Langabeer T, Hedges AL. Physician gender as a source of implicit bias affecting clinical decision-making processes: a scoping review. BMC Med Educ 2021; 171. https://doi.org/10.1186/ s12909-021-02601-2

47. Fortin M, Haggerty J, Almiral J, Bouhali T, Sasseville M, Lemieux M. Lifestyle factors and multimorbidity: a cross sectional study. BMC Public Health. 2014;14:686. https://doi.org/10.1186/1471-2458-14-686.

48. Mounce LTA, Campbell JL, Henley WE, Arreal MCT, Porter I, Valderas JM. Prediciting idident multiborbidity. Ann Fam Med. 2018;1(4):322-9.

49. Aaby A, Beuchamp A, O'Hara J, Maindal HT. Large diversity in Danish health literacy profiles: perspectives for care of long-term illness and multimorbidity. The European Journal of Public Health. 2019;30(1):75-80.

50. Masoompour M, Tirgari B, Ghazafnfari Z. The relationship between health literacy, self-efficacy, and self-care behaviors in diabeteic patients. Evid Based Care. 2017;7(3):17-25.

51. Dennison CR, McEntee ML, Samuel L, et al. Adequate health literacy is associated with higher heart failure knowledge and self-care confidence in hospitalized patients. J Cardiovasc Nurs. 2011;26(5):359-67.

52. Osborn CY, Cavanaugh K, Wallston KA, Rothman RL. Self-efficacy links health literacy and numeracy to glycemic control. J Health Commun. 2010;15(Suppl 2):146-58.

53. Xu XY, Leung AYM, Chau PH. Health Literacy, Self-Efficacy, and Associated Factors Among Patients with Diabetes. Health Lit Res Pract. 2018;2(2):e67-77.

54. Safeer RS, Keenan J. Health literacy: the gap between physicians and patients. Am Fam Physician. 2005;72(3):463-8.

55. Dinh H, Thuy T, Bonner A, Clark R, Ramsbotham J, Hines S. The effectiveness of the teach-back method on adherence and self-management in health education for people with chronic disease: a systematic review, JBI Database of Systematic Reviews and Implementation Reports 2016; 14 (1): 210-247. https://doi.org/10.11124/jbisrir-2016-2296.

56. Saunders C, Palesy D, Lewis J. Systematic review and conceptual framework for health literacy training in health professions education. Health Prof Educ. 2019;5(1):13-29.

57. Kaper MS, Winter AF, Bevilacqua R, et al. Positive Outcomes of a Comprehensive Health Literacy Communication Training for Health Professionals in Three European Countries: A Multi-centre Pre-post Intervention Study. Int J Environ Res Public Health. 2019;16(20):3923.

58. Chew LD, Bradley KA, Boyko EJ. Brief questions to identify patients with inadequate health literacy. Fam Med. 2004;36(8):588-94.

59. Campbell P, Lewis M, Chen Y, Lacey RJ, et al. Can patients with low health literacy be identified from routine primary care health records? A crosssectional and prospective analysis. BMC Fam Pract. 2019;20:101.

60. Bertakis KD. The influence of gender on the doctor-patient interaction. Patient Educ Couns. 2009;76(3):356-60. https://doi.org/10.1016/j.pec. 2009.07.022.

\section{Publisher's Note}

Springer Nature remains neutral with regard to jurisdictional claims in published maps and institutional affiliations. 